\title{
Anaerobic Digestion Creating Renewable Energy-The Ultimate Closed Loop System
}

\author{
J.Sarathkumar Sebastin
}

\begin{abstract}
This paper clarifies the significance of Anaerobic Digestion (AD) process. Sustainable power source from anaerobic assimilation gets little evaluation in the press when contrasted with other standard inexhaustible power age advances. It has not been so well known a sustainable power source when contrasted with hydropower sustainable power source or wind sustainable power source in the course of the most recent couple of years. Be that as it may, Renewable vitality from anaerobic processing is boosted the innovation will turn out to be increasingly mainstream in the coming years. Sustainable power source from anaerobic assimilation is amassed in America and Europe and eminently famous in India. Each 1 ton of sustenance waste discarded unnecessarily is in charge of 4.5 huge amounts of $\mathrm{CO}_{2}$ proportionate emanations. Advertisement gives a neighbourhood reasonable secure vitality source free of worldwide financial vitality changes and accessibility, where income is kept in the nearby economy as opposed to going to oil rich nations and multinationals. Sustainable power source from anaerobic processing is created by the consuming of methane. Sustainable power source from anaerobic assimilation is created in storehouses where specific microbes are added to natural waste. Sewage, vegetation, excrement, slaughterhouse waste and waste water would all be able to be separated in an anaerobic assimilation storehouse. At times, specific silage yields are developed for decay. The microbes are added to the waste and the disintegration happens without oxygen. The methane delivered during decay is scorched nearby, driving turbines and making inexhaustible power. Anaerobic processing isn't especially reasonable for little scale local sustainable power creation, to a great extent because of the space prerequisites for the storehouses and the sheer measure of waste required to delivering methane. Notwithstanding, sustainable power source from anaerobic assimilation can be delivered on a huge business scale, a training regular in the United States, taking waste from a wide area.
\end{abstract}

Keywords: Anaerobic Digestion (AD), Processing techniques, Applications.

\section{INTRODUCTION}

At present, a lot of our bio grade degradable waste, for example, nourishment, garden waste, card and paper is sent to landfill, where it separates to discharge methane, an incredible ozone harming substance. Anaerobic absorption (AD) is a treatment that fertilizers this loss without oxygen, creating a bio grade gas that can be utilized to produce power and warmth. Delivering 100 percent sustainable power source from our bio grade degradable waste helps handle environmental change, rather than adding to environmental change through land filling and cremation. Anaerobic Digestion (AD) is an organic procedure that happens normally when microbes separates natural issue in conditions with

Revised Manuscript Received on December 30, 2019.

* Correspondence Author

J. Sarathkumar Sebastin, Assistant Professor in Aeronautical Engineering, Kalasalingam Academy of Research and Education. almost no oxygen. It is adequately a controlled and encased form of the anaerobic breakdown of natural waste in landfill which discharges methane. Practically any natural material can be handled with $\mathrm{AD}$, including waste paper and cardboard (which is of too low an evaluation to reuse, for example in view of sustenance sullying), grass clippings, remaining nourishment, mechanical effluents, sewage and creature squander.

\section{AnAerobiC Digestion}

Anaerobic decay is an unpredictable procedure. It happens in three essential stages as the aftereffect of the movement of an assortment of microorganisms. At first, a gathering of microorganisms changes over natural material to a structure that a second gathering of life forms uses to shape natural acids. Methane-delivering (methanogenic) anaerobic microbes use these acids and complete the decay procedure. An assortment of components influence the proportion of absorption and bio grade gradable gas creation. The most significant is hotness.

Anaerobic tiny organisms networks might suffer temperatures running from beneath solidifying to beyond $58^{\circ}$ Centigrade $[\mathrm{C}]$, though they flourish best at hotness of about $37^{\circ} \mathrm{C}$ and $55^{\circ} \mathrm{C}$. Microbes movement, and in this way bio grade gradable gas creation, falls off altogether between about $104^{\circ}$ and $40^{\circ}$ and $52^{\circ} \mathrm{C}$ and bit by bit from $37^{\circ}$ to $0^{\circ} \mathrm{C}$. In the thermophilic range, decay and bio grade gas generation happen more quickly than at the mesophilic track. In any case, the procedure is exceedingly touchy to aggravations, for example, changes in nourish materials or hotness. Whereas every single anaerobic digester moderate the reasonability of tidy seeds and complaint delivering (pathogenic) living beings, the higher hotness of thermophilic assimilation consequence in progressively thorough devastation. Despite the fact that digesters worked in the mesophilic array need to be more, the procedure is less sensitive to bother or modification in working routine. The bio grade digester need to be kept at a fixed temperature, as fast deviations will aggravate bacterial action. In most of the areas of the United States, handling vessels involve some degree of safeguard as well as heating. A little establishments stream the coolant from their bio grade gas-controlled engines in or nearby the digester to preserve it warm, though others ingest some slice of the bio grade gas to warm the digester. The exchange offs in step ideal digester temperatures to intensify gas production while controlling costs are to certain degree complex. 
Concentrates on digesters at the north-focal regions of the regions demonstrate that extreme net bio grade gas production may happen in digesters kept up at hotness as low as $22.2^{\circ} \mathrm{C}$.

\section{Sustainable power source from anaerobic absorption in a world setting:}

Since the late eighteenth century, it has been perceived that combustible gases normally happen where natural issue deteriorates and the English researcher Humphry Davey recognized these gases as methane in 1808. Methane has been gathered and consumed since the appearance of sewage works. Creating sustainable power source from anaerobic assimilation grabbed pace into the 1940s, with Germany and France both utilizing anaerobic absorption to deliver methane during the Second World War. It has just been over the most recent couple of years that anaerobic processing sustainable power source has truly taken off in the treatment of rural waste.

Sustainable power source from anaerobic absorption gets little evaluation in the press when contrasted with other standard inexhaustible power age innovations. It has not been hydropower sustainable power source or wind sustainable power source in the course of the most recent couple of years. In any case, as government arrangements change and sustainable power source from anaerobic assimilation is boosted the innovation will turn out to be progressively well known in the coming years, with Feed-in Tariffs being especially significant in such manner. Sustainable power source from anaerobic processing is packed in America and Europe and remarkably well known in India.

\section{Sustainable power source from anaerobic assimilation:}

Sustainable power source from anaerobic assimilation is created by the consuming of methane. Working in a fundamentally the same as path to a gas-terminated power station (in reality, methane delivered by anaerobic assimilation can be added to ordinary gasterminated power plants or vehicles), sustainable power source from anaerobic processing is an extremely effective waste reusing and power producing source.

Sustainable power source from anaerobic processing is created in storehouses where specific microscopic organisms is added to natural waste. Sewage, vegetation, fertilizer, slaughterhouse waste and waste water would all be able to be separated in an anaerobic absorption storehouse. At times, specific silage yields are developed for decay. The microscopic organisms is added to the waste and the deterioration happens without oxygen (henceforth 'anaerobic'). The methane delivered during decay is scorched nearby, driving turbines and making inexhaustible power.

Anaerobic processing isn't especially reasonable for little scale local inexhaustible power generation, to a great extent because of the space necessities for the storehouses and the sheer measure of waste required to create methane. In any case, sustainable power source from anaerobic assimilation can be delivered on an enormous business scale, a training basic in the United States, taking waste from a wide district.

In the UK, ranches are ideal destinations to deliver sustainable power source from anaerobic assimilation. so prevalent a sustainable power source when contrasted with

Sustainable power source experts exist to prompt ranchers on the best innovation to utilize and how to send out this into the matrix.

\section{Anaerobic Digester Varieties:}

When forecasting the anaerobic processing framework incorporate cost, estimate, nearby atmosphere, and the accessibility and kind of natural feedstock material. Anaerobic digesters otherwise called bio grade digesters are made out of solid, steel, block, or plastic. They are formed like storehouses, troughs, bowls or lakes, and might be set underground or superficially. All anaerobic absorption framework plans fuse a similar fundamental segments:

- A pre-blending region

- A digester basin(s)

- A framework to develop the bio grade gas

- A framework to adopt or spread the gushing.

\section{Elementary kinds of digesters: Batch}

Cluster kind of digesters are the utmost straightforward to build. Their movement contains stacking the digester with natural materials and facilitating it to practice. Maintenance time depend on heat and diverse elements. When the assimilation is completed, the gushing is exiled and the procedures are rehashed.

\section{Continuous}

In the consistent digester type, natural materials are usually nourished into the digester. Unlike clump type digesters, constant digesters yield bio grade gas without the interruption of stacking material and discharging gushing. Few varieties of constant digesters are vertical chamber frameworks, fitting stream frameworks, and diverse chamber frameworks.

Legitimate plan, activity, and upkeep of consistent digesters produce a relentless and unsurprising supply of usable bio grade gas. They might be more qualified for huge scale tasks. The Anaerobic digester outline expenses differ generally. Frameworks can be assembled utilizing off-the-rack materials. There are likewise a couple of organizations that manufacture framework parts. Some complex frameworks have been structured by experts whose real center is inquire about, not minimal effort.

\section{Economics and Benefits of Anaerobic \\ Digesters:}

Before you introduce an anaerobic digester otherwise called a bio grade digester on your homestead or farm, you ought to investigate its monetary worth and potential advantages. A bio grade digester normally requires compost from in excess of 150 enormous creatures to cost adequately produce power. Anaerobic assimilation and bio grade gas generation can likewise diminish by and large working costs where expenses are high for sewage, rural, or creature squander transfer, and the gushing has monetary worth. Nonetheless, the waste management and smell decrease advantages of well-ordered anaerobic assimilation are accommodating growing interest, particularly for enormous scale domesticated animals activities, for example, dairies, feedlots, and slaughterhouses.

\author{
Published By: \\ Blue Eyes Intelligence Engineering
}




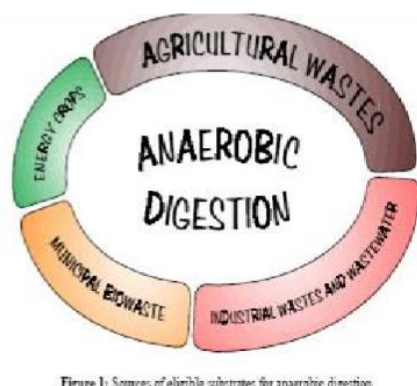

Figure 1: Sources of eligible substrates for anaerobic digestion

\section{MATERIALS AND METHODOLOGY}

\section{Working principle of Anaerobic Digestion:}

Bio grade digesters recoup methane as of creature excrement through a procedure called anaerobic assimilation. Methane is a gas that contains particles of methane with one iota of carbon and four molecules of hydrogen $\left(\mathrm{CH}_{4}\right)$. It is the significant part of the "normal" gas utilized in numerous homes for cooking and warming. It is unscented, dreary, and yields around 1,000 British Thermal Units (Btu) [252 kilocalories $(\mathrm{kcal})]$ of warmth vitality per cubic foot $(0.028$ cubic meters) when consumed.

Flammable gas is a petroleum derivative that was made ages back by the anaerobic deterioration of natural materials. It is frequently found in relationship with oil and coal.

Similar sorts of anaerobic microscopic organisms that produce gaseous petrol additionally produce methane today. Anaerobic microorganisms are probably the most established types of life on earth. They advanced before the photosynthesis of green plants discharged enormous amounts of oxygen into the air. Anaerobic micro organisms separate or "condensation" natural material without oxygen and produce "bio grade gas" as a waste item. (High-impact disintegration, or treating the soil, requires a lot of oxygen and produces heat.)

Bio gradegas created in anaerobic digesters comprises of methane (half $80 \%$ ), carbon dioxide (20\%-half), and follow levels of different gases, for example, hydrogen, carbon monoxide, nitrogen, oxygen, and hydrogen sulfide. The general level of these gases in bio grade gas relies upon the feed material and the executives of the procedure. Whenever consumed, a cubic foot ( 0.028 cubic meters) of bio grade gas yields around $10 \mathrm{Btu}(2.52 \mathrm{kcal})$ of warmth vitality per level of methane arrangement. For instance, bio grade gas made out of $65 \%$ methane yields 650 Btu for every cubic foot $(5,857$ $\mathrm{kcal} /$ cubic meter).

\section{Sludge:}

The material depleted from the anaerobic digester is called ooze. It is rich in enhancements (smelling salts, phosphorus, potassium, and more than twelve pursue segments) and is an astonishing soil conditioner. Any deadly blends (pesticides, etc.) that are in the digester feedstock material may finish up stuffed in the spouting. Thusly, it is basic to test the pro fluent before using it on a tremendous scale.

\section{RESULT AND CONCLUSION}

Anaerobic assimilation gives a significant chance to produce 100 percent sustainable power source from bio grade degradable waste. Research obviously shows the most supportable approach to treat our sustenance waste is to have separate week after week accumulations for treatment by AD. Solid support in the new Waste Strategy should imply that we begin to satisfy this potential, with the far reaching presentation of nourishment squander accumulations and the development of all the more AD plants over the UK.

\section{REFERENCES}

1. Eunomia (2006), "A Changing Climate for Energy from Waste", Dr Dominic Hogg, http://www.foe.co.uk/resource/reports/changing climate.pdf

2. DEFRA (2007), "Waste Strategy for England 2007", http://www.defra.gov.uk/environment/waste/strategy.

3. Friends of the Earth (2006), "Dirty Truths: Incineration and Climate Change", http://www.foe.co.uk/resource/briefings/dirty_truths.pdf

4. DEFRA (2004), "Review of Environmental and Health Effects of Waste Management: Municipal Solid Waste and Similar Wastes", http://www.defra.gov.uk/environment/waste/rese arch/health.htm

5. ERM (2007), "Carbon Balances and Energy Impacts of the Management of UK Waste Streams", http://www.resourcesnotwaste.org/members/conf-application-form/C arbon\&Waste (ERM).pdf.

\section{AUTHORS PROFILE}

J. Sarathkumar Sebastin working as Assistant Professor in Aeronautical Engineering, Kalasalingam Academy of Research and Education. The author has published papers in the areas of Solid propellants, UAV and propulsion. 